ECOLOGICA, Vol. 28, No 102 (2021), 293-300

https://doi.org/10.18485/ecologica.2021.28.102.22

Originalni naučni rad

UDC: $338.48-6: 502 / 504](497.11)$

652.2(497.11)

\title{
Železnički saobraćaj i razvoj ekoturizma u Republici Srbiji
}

\section{Railway transportation and ecotourism development in Republic of Serbia}

\author{
Aleksandra Vuković ${ }^{1}$, Milovan Vuković2*, Snežana Urošević ${ }^{3}$, Dejan Riznić4 \\ ${ }^{1}$ Akademija tehničko-umetničkih strukovnih studija, Odsek: Visoka železnička škola, Z. Čelara 14, 11000 \\ Beograd, Srbija \\ Academy of Technical and Artistic Vocational Studies, Department: Railway College, Z. Čelara 14, 11000 \\ Belgrade, Serbia \\ 2,3,4Univerzitet u Beogradu, Tehnički fakultet u Boru, V.J. 12, 19210 Bor, Srbija \\ University of Belgrade, Technical Faculty in Bor, V.J. 12, 19210 Bor, Serbia \\ *Autor za prepisku / Corresponding author
}

Rad primljen / Received: 05.09.2020, Rad prihvaćen / Accepted: 08.05.2021.

Sažetak: Rast popularnosti ekoturizma na globalnom planu, tokom minulih nekoliko decenija, može se pripisati većoj zabrinutosti ljudi za stanje životne sredine; posebno sa stanovišta zaštite prirodnih resursa. Ovaj vid tematskog turizma postaje sve značajniji u turističkoj industriji širom sveta. Poznato je da železnica, s druge strane, najpogodnije sredstvo prevoza sa stanovišta zaštite životne sredine, te da može značajno doprineti razvoju turizma u prostranim ruralnim i pograničnim krajevima. Za zemlje u razvoju, poput Srbije, ekoturizam je mogućnost za ubrzanje razvoja ovakvih oblasti bez poremećaja u životnoj sredini. Cilj istraživanja u ovom radu je procena postojećeg stanja i iznalaženje mera za razvoj ekoturizma u istočnoj Srbiji, zasnovanom na većem učešću železnice u kretanjima turista prema turističkim destinacijama u ovoj oblasti. Na osnovu izložene analize je pokazano da bi ponovno uspostavljanje železničkog saobraćaja moglo omogućiti bolje iskorišćenje prirodnih i kulturno-istorijskih potencijala u razvoju ekoturizma u ovoj oblasti.

Ključne reči: ekoturizam, železnički prevoz, istočna Srbija, prirodne vrednosti, revitalizacija železničke infrastrukture.

\begin{abstract}
The increase in ecotourism popularity at a global level, during the last several decades, one can attribute to the increased human concern for the environment; in particular, the state of natural resources. This type of thematic tourism has become more important in tourist industry world-wide. It has been known, for a long time, that rail is the most appropriate type of transportation in terms of enevironmental protection, and, it can significantly contribute to the development of ecotourism in vast rural and borderlands. For developing countries, like Serbia, ecotourism is an opportunity for accelerating economic development of rural areas without disturbance in their original enevironment. The aim of this paper is to assess current conditions and formulate measures to faster development of ecotourism in Eastern Serbia, based on larger share of rail in tourist travels to destinations in this area. It is shown, based on conducted analysis, that the revival of rail transportation could allow a better use of natural, cultural and histroical potential for faster development of ecotourism in this area.
\end{abstract}

Keywords: ecotourism, railway tourism, Eastern Serbia, natural values, rail infrastructure revitalization.

\footnotetext{
${ }^{1}$ e-mail: dr.milovanvukovic@yahoo.com.

2orcid.org/0000-0003-1715-1078, e-mail: mvukovic@tfbor.bg.ac.rs

${ }^{3}$ orcid.org/0000-0002-6647-0449, e-mail: surosevic@tfbor.bg.ac.rs

${ }^{4}$ e-mail:driznic@tfbor.bg.ac.rs
} 


\section{UVOD / INTRODUCTION}

Tokom poslednje zdravstveno-ekonomske krize globalnih razmera, izazvane virusom korona (Covid19), u većini zemalja je 2020. godine došlo do osetnog pada bruto-društvenog proizvoda (BDP). Privrede zemalja sa razvijenom turističkom privredom posebno su pogodile uvedene epidemiološke mere za sprečavanje zaraze, a najviše one o ograničavanju kretanja ljudi kako između država tako i unutar nacionalne teritorije. Tzv. zaključavanje, odnosno smanjenje učestalosti putovanja (svedeno samo na neophodne potrebe), ostavilo je pogubne posledice $u$ mnogim granama turizma. Ponajviše se one ogledaju u zanemarljivoj posećenosti tradicionalnih turističkih destinacija kao što su to mesta na obalama Mediterana i veliki evropski gradovi (metropole). Do sada nezabeležen pad odlazaka turista u letovališta na obalama mora svedoči o tome da su sunce, more i pesak, tzv. 3S (engl., sun, sea, sand) ili primorski turizam, i dalje dominantni vid turizma u evropskim i svetskim razmerama (Lytovchenko, 2016).

Vreme pandemije, s druge strane, podstaklo je mnoge turiste da deo odmora provedu na nekoj od domaćih turističkih destinacija. Pokazalo se da mnogi „zaboravljeni” predeli i oblasti predstavljaju mogućnost i izazov za turistički razvoj; naročito u pograničnim ruralnim krajevima (Madžgalj i dr., 2017). Ove oblasti postaju idealne za razvoj turizma posebnih interesovanja, ili tematskog turizma, budući da su turistička putovanja u ovom slučaju motivisana interesom za pojedinim atrakcijama i aktivnostima kao što su „sportovi, priroda, tradicionalni zanati, wellness, kultura, seoski turizam, događaji, festivali, nautika, itd" (Jovanović, 2013: 1). Raznovrsnost turističke ponude određenog geografskog područja, prema Svetskoj turističkoj organizaciji (WTO), počiva na resursima koje je moguće svrstati u pet celina a to su: (1) prirodni turistički resursi, (2) kulturno-istorijska baština, (3) klimatski uslovi, (4) infrastruktura i (5) turističke usluge i smeštaj. Infrastruktura podrazumeva prevoz i pristup turističkoj destinaciji (putevi, železničke pruge, luke, aerodromi, izvori energije, komunikacije itd).

Ekoturizam, pretežno zasnovan na prirodnim vrednostima, predstavlja vid tematskog turizma koji artikuliše izmenjene preferencije novih kategorija turista (pretežno mlađe starosne dobi), sa razvijenijom ekološkom svešću. Ekoturizam samim tim pruža mogućnosti za razvoj ruralnih oblasti na principima održivosti. Osobenost ekoturizma jeste briga o životnoj sredini, „,kako prirodnoj, tako i socio-kulturnoj” (Đurašević, 2008). Ovaj oblik tematskog turizma predstavlja značajnu komponentu integralnog i održivog razvoja sela budući de podstiče razvoj lokalne poljoprivrede, razvijanje novih delatnosti (poput rural- nog turizma), te zapošljavanje kroz stvaranje novih radnih mesta. Na razvoj ekoturizma u velikoj meri utiče stepen razvijenosti infrastrukture na određenom području; posebno kada je o saobraćajnim komunikacijama reč.

Polazna postavka ovog rada jeste ona o neraskidivoj povezanosti turizma i železnice. Saobraćaj je zapravo integrativni deo aktivnosti u okviru turističkog sektora. Transport, uz turističku ponudu i turističko tržište, predstavlja jednu od tri osnovne komponente turizma (Michniak, 2016). Poslednjih decenija XX veka osetno je opadala uloga železničkog saobraćaja u međunarodnom turizmu. Na prostoru nekadašnje SFRJ, na primer, učešće železnice u prevozu turista na tom prostoru smanjilo se sa $67,14 \%$ (1960. godine) na skromnih 8\% (1989); ponajviše zbog višestrukog povećanja korišćenja automobilskog prevoza - sa 10,77 na $68,39 \%$ u posmatranom periodu (Unković i Zečević, 2009). Železnički saobraćaj, uprkos svojoj značajnoj ulozi koju je imao u određenim fazama turizma, nije uspeo, kako primećuju Unković i Zečević, „da se dovoljno prilagodi izmenjenim uslovima na strani međunarodne turističke tražnje i pored konkretnih rezultata koji su u razvijenim turističkim zemljama ostvareni u njegovoj modernizaciji, povećanju komercijalnih brzina, povećanju ukupnog kvaliteta usluga i formiranju konkurentskih cena prevoza" (2009). Moglo bi se, s druge strane, očekivati da će prevoz železnicom zadržati važnu ulogu u domaćem turizmu, a posebno, u državama manje površine, veće fizičko-geografske raznovrsnosti, sa dobro razvijenom mrežom pruga itd.

Železnička infrustruktura, za razliku od ostalih vidova saobraćaja, ima ključnu ulogu u oblikovanju nekih turističkih destinacija. Zupčasta (uskošinska) železnica, na primer, odigrala je veliku ulogu u stvaranju materijalne osnove za razvoj turističkih destinacija u visokoplaninskim oblastima. Upravo su pruge uskog koloseka odigrale značajnu ulogu u saobraćajnom povezivanju visokih klimatskih i kasnije skijaških mesta u Švajcarskoj, dok pruge normalnog koloseka omogućavaju prilaze planinskom podnožju (Vujović i Spajić, 2011).

$U$ radu se polazi i od toga da veća upućenost turista na domaće destinacije, zbog dugotrajnosti pandemije, može delovati podsticajno za razvoj ekoturizma u zemljama sa razvijenom železničkom infrastrukturom kao i na bolje vrednovanje uloge železnice ne samo sa stanovišta ekoturizma već turističke privrede u celini. Posebno se to odnosi na značaj železnice za lokalno stanovništvo u mnogim ruralnim pograničnim krajevima Srbije u kojima je obustava ovog vida saobraćaja, zbog raznih okolnosti (na primer, poplava u Toplici 2020. godine; višestrukih iskliznuća vozova na liniji Zaječar - Niš), nane- 
la silne nevolje žiteljima brojnih sela u ovom i drugim krajevima sa sličnim problemima.

Železničke pruge nude dodatni potencijal za iskorišćenje ukoliko predstavljaju jedini vid saobraćaja u nekom kraju što je od posebne važnosti za ruralna, pogranična mesta (Boughey, 2013). U takvim okolnostima postoje mogućnosti za razvoj različitih oblika tematskog turizma - počev od ekoturizma, ekološkog seoskog turizma, izletničkog turizma i sl. Ovo može značajno doprineti povećanju životnog standarda ljudi koji žive u retko naseljenim a prostranim područjima, odnosno ispunjenju ciljeva održivog razvoja preko, na primer, smanjenja siromaštva. Ekoturizam u Srbiji, nažalost, još se nalazi u početnoj fazi razvoja. Glavni razlozi za ovakvo stanje su nedovoljna razvijenost turističkih destinacija a isto tako i nedostak odgovarajućih promotivnih aktivnosti usmerenih na podizanje javne svesti o principima ekoturizma (Beljanski, 2018).

$\mathrm{U}$ ovom radu se sagledavaju mogućnosti za razvoj aktivnosti ekološkog turizma u ruralnim predelima u kojima postoji železnička infrastruktura. Cilj rada je da se razmotre ne samo saobraćajni efekti aktuelne i planirane rekonstrukcije pruga, u okviru železničke infrastrukture Srbije, već i posredni i očekivani učinci u oblasti ekoturizma. Pažnja je u tom smislu usmerena i na mogućnosti približavanja prirodnih vrednosti istočne Srbije. Ovaj pogranični region, koji u geografskom pogledu uključuje Karpatsko-balkansku oblast, mnogim turistima iz velikih gradova, kao i iz ostalih delova Srbije, još nije predstavljen na odgovarajući način, te se unapređenje saobraćajne infrastrukture nazire kao moguće rešenje.

\section{TEORIJSKI OKVIR / THEORETICAL FRAMEWORK}

Turistička kretanja se u okviru ekoturizma sagledavaju na različite načine. Ekoturizam se obično vezuje za „prirodno orijentisan turizam”, „turizam posebnih interesovanja", a ponekad se ukazuje na dodirne tačke sa oblicima turizma kao što su „avanturistički”, „ruralni” i „alternativni” (Đukin i dr, 2018). Slično značenje kao ekoturizam imaju i sledeći termini: „zeleni turizam”, „ekološki odgovoran turizam”, „turizam bez ugljenika” i „turizam koji ne proizvodi ugljenik" (Janković i dr., 2020). Orijentisanost turista na prirodne resurse je nesumnjivo osnovno obeležje ekoturizma. U zaštićenim prirodnim dobrima, poput specijalnih prirodnih rezervata, posetici upražnjavaju one oblike turizma koji streme unapređenju prirodnih resursa, a takvi su: „ekoturizam, naučno-istraživački turizam, posmatranje ptica, izletnički i drugi oblici turizma utemeljeni na očuvanju i unapređenju prirodnih vrednosti" (Štetić i Trišić, 2020). Ekoturizam, u odnosu na ostale oblike turizma zasnovane na prirodnim resursima, ističe $u$ prvi plan obrazovanje, rekreaciju i avanturu.

Ekoturizam, uprkos tome što teži ispunjenju ciljeva održivog razvoja, ne bi trebalo izjednačavati sa održivim turizmom. Principi održivosti se primenjuju u svim delatnostima, uključujući i turističku privredu. Obezbeđenje sklada između ekonomskih, ekoloških i socijalno-kulturnih aspekata razvoja jeste izazov i za masovne oblike turizma (primorski i gradski) i za turizam posebnih interesovanja. Ekoturizam se, s druge strane, odnosi na tačno određene turističke aktivnosti, specifičnosti ponašanja turista i izged turističke destinacije (Ivanović i dr., 2016). Pogrešno bi bilo takođe pojmovno izjednačiti ekoturizam sa ruralnim turizmom koji poslednjih decenija dobija sve više na značaju; ponajviše zbog negativnih demografskih procesa koji su ponegde doveli do potpune socijalne devastacije. Ruralni turizam u svojoj ponudi, pored ekoturizma, uključuje i čitav niz drugih proizvoda među kojima su: agroturizam, kulturni turizam, manifestacioni turizam, rekreacija u prirodi, gastronomski turizam (organska hrana) i kombinovani oblici turizma (Milenković i Tasić, 2013). Ekološki turizam ima mogućnost da revitalizuje zapuštena sela, ruralne prostore, te zapuštene turističke destinacije. Aktivnosti na iskorišćenju prirodnih potencijala, s kojima određeno područje raspolaže, mogle bi podstaći ljude da „ostanu na svojim ognjištima i daju doprinos njihovom razvoju” (Mladenović i Bojičić, 2020). Ekoturizam kao segment ruralnog turizma, naposletku, predstavlja uporište za razvoj aktivnog sportskog turizma (Đurović i dr., 2020). Ovaj deo sportskog turizma podrazumeva bavljenje turista na odabranoj destinaciji sportovima kao što su: ribolov, skijanje, alpinizam, planinski biciklizam, paraglajding itd. Ostali segmenti sportskog turizma uključuju odlaske turista na praćenje sportskih događaja kao i posete sportskih objekata (stadiona, muzeja i sl.).

Železnički turizam, u smislu iskorišćenja potencijala prirodnih vrednosti predela, može se posmatrati kao podvrsta tzv. usporenog turizma (slow tourism) koja poslednjih decenija postaje sve privlačnija (Lumsdon \& McGrath, 2011). Ono što je osobeno za ovu vrstu turizma odnosi se na sporost i drugačije vrednovanje vremena; usredsređenost na određenu lokaciju i aktivnosti na destinaciji; način transporta i s njim povezano specifično iskustvo tokom prevoza; te razvijena ekološka svest turista (Reis \& Jellum, 2012).

Putovanje železnicom može poboljšati utisak o čitavom turističkom aranžmanu. Turisti koji tokom putovanja koriste ovo prevozno sredstvo pamte, kako to primećuje Minić, „pejsaže, ljude, životinje, a enterijer samog voza takođe je specijalni efekat. Spoljašnji pejsaži, vozni enterijer i udobnost mogu biti indikatori za bolje turističko iskustvo" (Minić, 2017). 
Železnica se nameće kao najinteresantniji vid saobraćaja sa stanovišta razvoja ekoturizma budući da najmanje narušava prirodni ambijent predela kroz koji prolazi pruga, te najmanje zagađuje životnu sredinu. To železnici daje preimućstvo u odnosu na ostale vidove saobraćaja. Železnički turizam ne treba smatrati novim fenomenom. Premda putovanja železnicom, koja krajem XIX veka postaju deo svakodnevice ljudi u razvijenim zemljama, nisu preduzimana u cilju odmora i turizma, uvedene železničke linije prerasle su vremenom $u$ turističke rute zbog lepote predela, udobnosti tokom vožnje i ostalih pogodnosti. Nekolike pruge izgrađene na razmeđu XIX i XX veka u živopisnim planinskim predelima $-u$ Francuskoj, Italiji, Austriji, Švajcarskoj, Indiji i drugde - postale su deo svetske baštine zahvaljujući ondašnjim tehnološkim dostignućima kao i socijalno-kulturnoj i ekonomskoj vrednosti. Na lepotama predela kroz koje prolaze ove pruge osmišljen je poznat turistički proizvod Orijent ekspres (Orient Express). Luksuzno putovanje železnicom koje je povezivalo Pariz, Milano i Veneciju kasnije je, počev od 1906. godine obuhvatalo i Srbiju, jer se na ruti našlo više pridodatih gradova sa jugoistoka Evrope (Beograd, Sofija, Atina i lstanbul).

\section{MATERIJALI I METODE / MATERIALS AND METHODS}

Zdravstveno-ekonomska kriza se tokom 2020. godine dobrano odrazila i na ekoturizam koji je tokom minule dekade beležio najveći rast u turističkoj privredi (Fletcher, 2014). O međusobnoj povezanosti ekoturizma i stanja životne sredine u uslovima najnovije pandemije postoje studije koje upućuju na kompleksnost ovog međuodnosa. Nesumnjivo je da pandemija Covid-19, uzrokovana koronavirusom, nudi jedinstvenu priliku za izvođenje različitih tipova istraživanja, uključujući i tzv. eksperiment u prirodnim uslovima (Buckley, 2020).

U ovom istraživanju je, polazeći od formulisanog istraživačkog pitanja, primenjen metod slučaja kako bi se sagledalo aktuelno stanje železničke infrastrukture u Srbiji i procenili potencijali za razvoj železničkog turizma. Analize ove vrste omogućava podlogu za diskusiju činilaca koje bi trebalo uzeti u razmatranje prilikom planiranja i realizacije turističkih putovanja železnicom. Srbija nije slučajno uzeta za jedinicu posmatranja. Ova zemlja, čije pruge (ukupne dužine oko $4.000 \mathrm{~km}$ ) ne omogućavaju brzu vožnju, nudi turistima koji putuju železnicom izvanredan osećaj po osnovu uživanja u brojnim prirodnim vrednostima.

Korišćenje metoda slučaja je opravdano u situacijama kada se pretpostavlja veći stepen povezanosti proučavanog fenomena sa raznovrsnim činio- cima sredine. Ovaj metod se svodi na „empirijsko ispitivanje kojim se istražuje savremeni fenomen unutar njegovog stvarnog, životnog konteksta, posebno kada granice između fenomena i konteksta nisu jasno uočljive" (Yin, 1994). Metod slučaja iziskuje trud istraživača u smislu da proučavani fenomen jasno omeđi prostorno-vremenskim korordinatama. Sam naziv metoda, pri tome, upućuje na to da se radi o nekom izdvojenom slučaju, nekom primeru manifestacije koji je pogodan za preduzeti istraživački postupak i analizu.

Detaljno opisivanje i objašnjavanje odabranog slučaja omogućava proveru nekih opštih stavova i hipoteza (Šijaković, 2008). Dobra strana metoda slučaja ogleda se i u tome što pruža mogućnost istraživačima sa skromnim vremenskim i materijalnim resursima da dođu do saznanja koja mogu biti potencijalno korisna Naposletku, ovaj metod se ne svodi samo na opisivanje, objašnjavanje i razumevanje, već i na predviđanje i/ili kontrolisanje pojave koja je predmet istraživanja (Vuković i Štrbac, 2019).

\section{REZULTATI I DISKUSIJA / RESULTS AND DISCUSSION}

Železnički saobraćaj u Srbiji ima dugu tradiciju. Prva pruga, dužine $63 \mathrm{~km}$, izgrađena je i puštena u saobraćaj 1854. godine. Posle Prvog svetskog rata ukupna dužina železničkih pruga iznosila je 1.857 $\mathrm{km}$, da bi 1995. godine ukupna dužina pruga u Srbiji narasla na $3.819 \mathrm{~km} ; 1.254 \mathrm{~km}$ su elektrificirana (33\%). Na osnovu predočenih podataka moglo bi se pretpostaviti da ukupna dužina pruga u Srbiji omogućava dobru osnovu za razvoj turizma i, eventualno, povećanje broja turista koji za prevoz koriste voz. Izvor dodatnog optimizma je i činjenica da se minulih decenija nije smanjivala ukupna dužina pruga. Potpuniju sliku o tome da li je železnička mreža prilagođena zahtevima turističkog tržišta moguće je steći ukoliko se sagleda da li su i na koji način važniji turistički centri povezani sa železničkim prugama, te kakvog je stanje pruga u pogledu amortizovanosti ekspolatacionih karakteristika, opremljenosti signalno-sigurnosnim uređajima, informacionim sistemima itd.

\subsection{Prirodni potencijali za razvoj ekoturizma u istočnoj Srbiji /}

Natural potentials of the ecotourism development in Eastern Serbia

Najprivlačnija turistička odredišta u Srbiji predstavljaju banje, planine pogodne za razne sportske aktivnosti (ponajviše za skijanje), jezera, najveći gradovi sa raznovrsnim kulturnim, sportskim i ostalim sadržajima, te ostala mesta i predeli sa bogatim nasleđem prirodnih vrednosti (parkovima, pećina- 
ma, zelenim površinama) i kulturno-istorijskom baštinom. S obzirom na to da je težište analize u ovom radu na mogućnostima većeg iskorišćenja turističkih potencijala u oblasti Karpatsko-balkanskih planina, odnosno istočne Srbije, korisno je sagledati udaljenosti najvažnijih turističkih destinacija od železničke pruge. Istočna Srbija se proteže od Dunava na severu do Nišave na jugu - uključuje teritorije tri okruga (Borski, Zaječarski i Pirotski) kao i područja opština Kučevo, Žagubica, Despotovac, Aleksinac, Svrljig i Niška Banja.

Banje, veliko bogatstvo Srbije, prirodna su odlika i ovog dela planinsko-kotlinske Srbije. Brestovačka banja, proglašena još u vreme Kneževine Srbije za banjsko mesto, nalazi se na samo $10 \mathrm{~km}$ razdaljine od Bora kroz koji vodi železnička pruga Beograd - Zaječar. Gamzigradska banja je udaljena $12 \mathrm{~km}$ od Zaječara, regionalnog železničkog čvora, iz koga idu pruge prema Beogradu, Negotinu i Nišu. Niška banja, udaljena svega $10 \mathrm{~km}$ od Niša, vezana je za železnički krak Koridora 10: Niš - Dimitrovgrad. Udaljenije banje od železničkih pravaca su Sokobanja (30 km od Aleksinca) i Zvonačka banja (50 km od Pirota) tako da je u ovim slučajevima neophodno obezbediti turistima korišćenje kombinovanog saobraćaja; u ovom slučaju, železničko-autobuskog.

Stara planina - najznačajnija planinska destinacija Karpatsko-balkanske Srbije - udaljena je 30 km od Pirota, a druga po blizini je železnička stanica u Knjaževcu na pravcu Zaječar - Niš. Značajne su i ostale planine koje nisu mnogo udaljene od železničkih pruga; na primer, Veliki krš, Stol, Mali krš, Crni vrh, Beljanica, Homoljske planine, Tupižnica, Tresibaba, Suva planina i druge. Letnji segment planinskog turizma (planinski biciklizam, sakupljanje lekovitog bilja, šetnje) imaće u budućnosti veći značaj u odnosu na zimski turizam zbog štetnih posledica globalnih klimatskih promena (Đukin i dr., 2018).

Tri turistički značajna jezera u ovom delu Srbije (Đerdapsko, Bovansko i Borsko jezero) nisu mnogo udaljena od Majdanpeka (17 km), Aleksinca (15 $\mathrm{km})$, odnosno Bora $(14 \mathrm{~km})$. Ostale prirodne turističke potencijale u ovoj oblasti - nacionalni park Đerdap, poznate pećine (Bogovinska, Zlotska, Rajkova, Dubočka, Resavska, Cerjanska, Prekonoška i Jelašnička) - kao i raznovrsno kulturno-istorijsko nasleđe moguće je učiniti dostupnijim turistima razvijanjem kombinovanog sabraćaja čiju okosnicu predstavlja prevoz železnicom.

Ogromno prirodno bogatstvo predstavljaju i šume koje zauzimaju preko $40 \%$ teritorije istočne Srbije (Jovanović et al., 2020). Prostrano planinsko područje Južnog Kučaja ponekad se slikovito naziva „plućima Srbije” poput šuma Amazonije za koje se odomaćila sintagma „pluća planete”. Deonica pruge
Beograd - Zaječar između Kučeva i Bora posebno je interesantna ekoturistima budući da prolazi kroz živopisne predele obrasle gustim šumama u okolini Majdanpeka, prateći pri tome tok zlatonosnog Peka.

Bor sa svojom okolinom predstavlja više nego privlačnu turističku destinaciju za poklonike ekoturizma. U blizini već pomenutog Borskog jezera, čija voda tokom leta dostiže temperaturu od $24^{\circ} \mathrm{C}$, prostiru se proplanci, pašnjaci, planina Crni vrh, te nekadašnja vulkanska kupa Tilva Njagra (Crno brdo). Obale ovog jezera krase uređene plaže (betonske, kamene i peščane) a njegovi posetioci, osim plivanja, uživaju i u vožnji čamcima. U neposrednoj blizni jezera nalazi se kompleks sportskih terena - idealan za pripreme sportista - kao i trimstaze koje izlaze na trasu Crnovrške pruge koja vodi ka Boru. Nedaleko od Borskog jezera su Brestovačka banja, Zlotske pećine i Lazarov kanjon, a nešto dalje, prema jugu i zapadu, planina Malinik i Dubašnica.

S druge strane, severno od Bora (prema Majdanpeku), nalazi se nekoliko planina srednje visine; pre svega Veliki krš koji dostiže visinu od $1.148 \mathrm{~m}$. Severnije od ove planine nalazi se Mali krš čiji najviši vrh dostiže visinu od $929 \mathrm{~m}$. Vrh Malog krša, s obzirom na to da je dugačak 6 a širok $2 \mathrm{~km}$, predstavlja omiljenu trasu za bicikliste iz čitave Evrope. Sa zapadne strane ovih planina prolazi pruga između Majdanpeka i Bora, sa stanicama u mestima Debeli Lug, Leskovo, Vlaole i Brezonik.

Slaba saobraćajna povezanost Bora i okoline sa ostalim delovima zemlje, uprkos bogatog prirodnog potencijala, predstavlja jedno od glavnih slabosti za razvoj turizma u ovom kraju. Veliki nedostatak je još prisutna slika o Boru kao izrazito zagađenom kraju zbog duge tradicije rudarenja i metalurgije bakra (Voza i Fedajev, 2020). Bolje saobraćajno povezivanje, ne samo železnicom, već i planiranom izgradnjom tzv. brze saobraćajnice od Markovca do Bora, stvoriće posve novi milje za razvoj ekoturizma, počev od Borskog jezera (koje se, za sada, uglavnom koristi prema konceptu masovnog turizma) pa do ostalih turističkih destinacija.

\section{2. Železnički saobraćaj i unapređenje ekoturizma $u$ istočnoj Srbiji /}

Railway transportation and improvement of ecotourism in Eastern Serbia

Ukoliko bi se pošlo od dužine pruga, odnosno prosečne kilometraže na svakih $1.000 \mathrm{~km}^{2}$, te njihove povezanosti sa nekim od pomenutih turističkih destinacija (nadaleko poznatim u nacionalnim okvirima), mogao bi se steći utisak da je stanje zadovoljavajuće. Tehnička ispravnost i funkcionalnost pruga ipak dovode ovu ocenu u pitanje. Postojeće 
stanje železničkih pruga karakteriše velika amortizovanost i dotrajalost svih elemenata, posebno u istočnoj Srbiji, što stvara probleme smanjenja brzine, opterećenja po osovini, smanjenje propusne moći itd. Slična situacija je i kada su u pitanju signalno-sigurnosna postrojenja, telekomunikacioni sistemi veza i sl. Ohrabruje ipak da su prošle godine otpočeli radovi na rekonstrukciji pojedinih deonica na železničkom pravcu Beograd - Zaječar - Niš. Reč je deonicama između Požarevca i Kučeva, odnosno između Knjaževca i Svrljiga. Revitalizacija ovih pruga donela bi ne samo saobraćajne i ekonomske koristi već i bolje iskorišćenje zapostavljenih turističkih potencijala Srbije.

Revitalizacija železničke infrastrukture doprineće i razvoju ekoturizma na ovom području. Posebno se to odnosi na krajeve kroz koje prolazi linija Zaječar - Beograd na kojoj je prevoz železnicom obustavljen pre više od 10 godina. Radovi na rekonstrukciji najlošijeg dela pruge (od Požarevca do Majdanpeka) privode se, na sreću, kraju. Potpuno obnavljanje saobraćaja na čitavom ovom pravcu moglo bi se očekivati za godinu-dve. Isto se može reći i za deonicu od Svrljiga da Knjaževca, posebno njen deo koji prolazi kroz živopisni kanjon Svrljiškog Timoka.

Postojeća iskustva o korišćenju železničkog prevoza primarno u turističke svrhe govore u prilog tezi da bi trebalo unaprediti kvalitet železničkog saobraćaja budući da potencijalno može doprineti razvoju svih vidova turizma, a posebno različitih oblika turizma posebnih interesovanja. Svetli primeri su već poznati turistički železnički proizvodi: voz „Romantika” i „Šarganska osmica”. Ideja da se na prugama nađe srpski Orijent ekspres javila se u vreme obeležavanja 110 godina železnice u Srbiji, 1994. godine, kada je upriličeno putovanje tzv. Šetnim vozom od Beograda do Topčidera. Pre četvrt veka, 1. juna 1996. godine, realizovana je i prva promotivna vožnja vozom „Romantika” od Topčidera do Ljubičeva. Iste godine, pošto je ovo putovanje pobudilo veliko interesovanje turista, organizovana je prva promotivna vožnja ovim vozom do Sremskih Karlovaca, koja je kasnije postala redovna komercijalna linija. Osim Sremskih Karlovaca, organizovana su komercijalna putovanja do Vršca, Bele Crkve, Palića, Požarevca, Smedereva, Despotovca i Jagodine. U sastavu kompozicije ovog voza nalazi se i vagon za prevoz bicikala što je posebna pogodnost za ekoturiste.

Vozom „Romantika” je 2018. godine, tokom sezone (od aprila do septembra), organizovano šest komercijalnih putovanja na liniji Topčider - Jagodina. Usluge ovog voza je koristilo 2.287 putnika - najviše u junu (458) i krajem avgusta (467) - što je pred- stavljalo povećanje od $18,19 \%$ u odnosu na prethodnu godinu kada je ostvareno 1.871 putovanje. Povećanje broja putnika se odrazilo na osetno povećanje ostvarenog prihoda; sa $561.452,00$ na 886.144,00 dinara.

Osim redovnih komercijalnih putovanja kompanija „Srbija voz” omogućava korišćenje kompozicije „Romantika” po osnovu zakupa. Zatvorene grupe, pored opisanih relacija na kojima "Romantika” saobraća, imaju slobodu izbora željene destinacije. Novija ispitivanja pokazuju da potencijalne putnike vozom „Romantika” najviše interesuju predeli u istočnoj Srbiji, odnosno železnički pravci: Požarevac - Zaječar, Zaječar - Prahovo, Zaječar - Niš, te Markovac - Resavica. Dosadašnja praksa iznajmljivanja ovog voza nije se pokazala uspešnom jer je zakup podrazumevao fiksnu cenu, nezavisno od broja putnika. Ovaj pristup se tokom primene pokazao kao neefikasan budući da ukupni troškovi pokretanja garniture voza zavise i od broja angažovanih kola. „Srbija voz" otuda nastoji da za naredne sezone, odmah po okončanju pandemije Covid-19, utvrdi cene zakupa koje će uzeti u obzir ne samo dužinu odabrane relacije već i broj zainteresovanih putnika u grupi.

\subsection{Potreba saradnje železnice i turizma /}

The need of cooperation between railway and toursim

Saradnja preduzeća koja se bave železničkim prevozom sa putničkim i turističkim agencijama od velike važnosti je za razvoj ekoturizma. Rezultati te saradnje često odstupaju od očekivanja. Saradnja bi bila uspešnija ukoliko bi se uspešnije realizovale tarifske ponude, bolje koristili pojedini kapaciteti, razvili privlačniji turistički proizvodi, uz veće korišćenje železnice kao prevoznika i ukupnih železničkih turističkih sadržaja.

Železnica, pored preduzimanja odgovarajućih organizacionih mera, može doprineti kvalitetnijem prevozu turista i svih putnika ukoliko: (1) intenzivira saradnju sa turističkim organizacijama, kako pri izradi programa rada, tako i kod neposrednog odvijanja i saobraćajnog i turističkog prometa; (2) uspostavi neposredniju i konkretniju saradnju sa drugim organizacijama u ekonomskom, tehničko-tehnološkom i komercijalnom smislu radi pružanja kvalitetnijih transportnih i ukupnih turističkih usluga; (3) istražuje unutrašnje i međunarodno turističko tržište; (4) usklađuje investicionu politiku železničkih i turističkih organizacija u oblastima gde se prepoznaje zajednički interes; (5) aktivno učestvuje u izradi propagandnih materijala; (6) obezbeđuje uslove efikasne prodaje, strateški prati prevoz turista po saobraćajnim granama i po odgovarajućoj strukturi; te (7) 
primenjuje koncepcije i strategije marketinga i savremenog menadžmenta.

Oslanjanje na principe marketinga realizovane transportne usluge je neophodno da bi se postigli željeni rezultati u oblasti turizma, kao i u prevozu turista železnicom. Iz rastuće međuzavisnosti turizma i železnice proističe potreba saradnje na planiranju i realizovanju tržišno-zahtevne turističke ponude. Neophodno je u boljem svetlu predstaviti potencijale turističkih destinacija, poput onih opisanih na primeru Bor i okoline, pošto aktuelni imidž u javnosti ne odgovora pravoj slici stanja.

Po okončanju najnovije pandemije moglo bi se očekivati trajnija orijentacija turista prema ekoturističkim destinacijama, odnosno korišćenju domaće turističke ponude. Ljudi će u predstojećem periodu, po svoj prilici, izbegavati udaljenije destinacije delom iz želje da smanje rizik od infekcije, a delom i zbog uvođenja novih postupaka kontrole na granicama (Luković i Stojković, 2020). Transformacija globalnog turizma prema oblicima turizma koji su u skladu s principima održivog razvoja omogućava i železnici da svoju povezanost s turizmom sagleda na drugačiji, inovativniji način.

\section{ZAKLJUČAK / CONCLUSION}

Ekoturizam predstavlja veliku razvojnu šansu za prostrano područje istočne Srbije koje obiluje raznolikim prirodnim bogatstvom i kulturno-istorijskim nasleđem. Postojeća mreža železničkih pruga u Karpatsko-balkanskoj Srbiji može približiti turističke destinacije potencijalnim turistima. Preduzeća u oblasti prevoza putnika železnicom trebalo bi da iskoriste ove okolnosti i da promovišu svoju turističku ponudu kao što je, na primer, poznat turistički proizvod - voz „Romantika”. Da bi se „Romantika” uskoro kretala istočnom Srbijom, nije dovoljno samo puštanje pruga u saobraćaj (posle višegodišnje rekonstrukcije) već in treba na odgovarajući način prilagoditi i predstaviti široj javnosti; prvenstveno intenzivnijim promotivnim aktivnostima. Obnavljanje redovnog železničkog saobraćaja na postojećoj mreži predstavlja važan preduslov razvoja ekoturizma na ovom području. $U$ tom smislu najvažnijim se čini redovnost $i$ pouzdanost železničkog prevoza kako bi se obezbedilo njegovo kombinovanje s drugim vidovima saobraćaja. Svekolike aktivnosti na revitalizaciji železničkog saobraćaja su potpuno u saglasnosti i sa održivin razvojem turizma koji se posebno otelovljuje u ekoturizmu.

\section{Zahvalnost / Acknowledgement}

Istraživanja predstavljena $u$ ovom radu su urađena uz finansijsku podršku Ministarstva prosvete, nauke i tehnološkog razvoja Republike Srbije, u okvi- ru finansiranja naučno istraživačkog rada na Univerzitetu u Beogradu, Tehničkom fakultetu u Boru, prema ugovoru sa evidencionim brojem 451-03-9/202114/ 200131.

\section{LITERATURA / REFERENCES}

[1] Beljanski, N. (2018), Ekološka odgovornost turizma, TIMS Acta, 12, 37-45, 2018.

[2] Boughey, J. (2013), From transport's golden ages to an age of tourism: L.T.C. Rolt waterway revival and railway preservation in Britan, 1944-1954, The Journal of Transport History, 34(1), 23-38.

[3] Buckley, R. (2020), Pandemic travel restrictions provide a test of net ecological effects of ecotourism and new research opportunities, Journal of Travel Research, pp. 1-3.

[4] Đukin, A., Mihailović, M., Petrović, J., Stavretović, N. (2018), Značaj rekreacionog potencijala Stare planine za unapređenje održivog turizma, Ecologica, 25(89), 169-174.

[5] Đurašević, S. (2008), Turistička putovanja, CID, Podgorica.

[6] Đurović, S., Perović, A., Šiljak, V., Antonijević, S., Veselinović, J., Baćevac, S.(2020), Održivost razvoja sportskog turizma kao privredne grane: uticaj COVID-19, Ecologica, 27(100), 699-706.

[7] Ivanović, V., Gašić, M., Perić, G., Krulj Mladenović M. (2016), Zeleni turizam kao deo zelene ekonomije u funkciji buduće održivosti, Ecologica, 23(84), 790-794.

[8] Fletcher, R. (2014), Romancing the wild: Cultural dimensions of ecotourism, Duke University Press, Durham; NC.

[9] Janković, M., Ivannikov, N., Jovanović, L., Gajdobranski, A. (2020), Doprinos zelene ekonomije razvoju ekoturizma i organskoj proizvodnji, Ecologica, 27(98), 217-223.

[10] Jovanović, V. (2013), Tematski turizam, Beograd, Univerzitet Singidunum.

[11] Jovanović, V., Paunković, J., Marjanović, N. (2020), Analiza stavova građana o ekološkoj bezbednosti na teritoriji lokalne samouprave Boljevac, Ecologica, 27(98), 306-311.

[12] Luković, S., Stojković, D. (2020), Covid-19 pandemic and global tourism, Hotel and Tourism Management, 8(2), 79-88.

[13] Lumsdon, L.M., McGrath, P. (2011), Developing a conceptual framework for slow travel: a grounded theory, Journal of Sustainable Tourism, 19 (3), 265-279.

[14] Lytovchenko, I.V. (2016), Rural green tourism is new direction of tourist services, Međunarodna 
naučno-stručna konferencija Modernizacija privrede za povećanje javne svesti, Poltava, Ukrajina, Zbornik radova, str. 116.

[15] Madžgalj, J., Milošević, O., Dragojlović, V. (2017), Unapređenje ekološkog turizma kroz model proizvodnje organske hrane, Ecologica, 24(86), 300304.

[16] Michniak, D. (2016), Role of railway in tourism: selected problems and examples in Slovakia, Questiones Geographicae, 35(4), 107-120.

[17] Milenković, S., Tasić, J. (2013), Organska hrana kao perspektivni proizvod Srbije, Ekonomske teme, 51(2), 411-424.

[18] Minić, N. (2017), Železnice kao energetsko efikasan i turistički potencijal Srbije, Ecologica, 24(86), 447-451.

[19] Mladenović, M., Bojičić, R. (2020), Razvoj ekoturizma u opštini Štrpce - mogućnosti i perspektive, Ecologica, 27(98), 232-239.

[20] Reis, A., Jellum, C. (2012), Rail trail development: A conceptual model for sustainable tourism, Tourism Planning \& Development, 9(2), 133-147.
[21] Šijaković, I. (2008), Sociologija, Univerzitet u Banjoj Luci, Ekonomski fakultet, Banja Luka.

[22] Štetić, S., Trišić, I. (2020), Prirodni resursi za razvoj ekoturizma Specijalnog rezervata prirode "Obedska bara”, Ecologica, 27(98), 224-231.

[23] Unković, S., Zečević, B. (2009), Ekonomika turizma, CID; Ekonomski fakultet, Beograd.

[24] Voza, D., Fedajev, A. (2020), Strategic approach to the development of ecotourism in Bor District, Serbia, Hotel and Tourism Management, 8(2), 89100.

[25] Vujović, S., Spajić, J. (2011), Značaj saobraćajne infrastrukture za razvoj turizma. U: Koridor $10 \mathrm{u}$ funkciji društvenog razvoja Srbije, Centar za strateška istraživanja nacionalne bezbednosti, Beograd, Ribarska banja, 28-30. januar, 2011, Zbornik radova, str. 135-148.

[26] Vuković, M., Štrbac, N. (2019), Metodologija naučnih istraživanja, Univerzitet u Beogradu; Tehnički fakultet, Bor.

[27] Yin, R.K. (1994), Case Study Research, Thousands Oaks, Sage. 